\title{
miR-183-3p suppresses proliferation and migration of keratinocyte in psoriasis by inhibiting GAB1
}

\author{
Ting Liu* ${ }^{*}$, Xiaoyan Zhang and Yujuan Wang
}

\begin{abstract}
Background: MicroRNAs (miRNAs) target genes involved in the hyperproliferation of keratinocytes or immune dysfunction of psoriasis. This study prospectively determined the involvement of miR-183-3p in the pathogenesis of psoriasis.

Methods: Differentially expressed miR-183-3p between psoriatic lesional and non-lesional skin were determined by quantitative RT-PCR and in situ hybridization (ISH). CCK8 and wound healing assays were performed to assess cell viability and migration of human keratinocyte cell line ( $\mathrm{HaCaT}$ ). The target of miR-183-3p was validated by luciferase activity assay.

Results: Lower miR-183-3p expression was observed in psoriatic lesional skin compared to psoriatic non-lesional skin. MiR-183-3p over-expression inhibited the viability and migration of $\mathrm{HaCaT}$ cells, while inhibition of miR-183-3p promoted the viability and migration of HaCaT cells. Moreover, miR-183-3p could bind to the 3' UTR of GAB1 (growth factor receptor binding 2-associated binding protein 1) and decrease the mRNA and protein expression of GAB1 in HaCaT cells. In addition, higher GAB1 expression was observed in psoriatic lesional skin than psoriatic non-lesional skin.

Conclusion: MiR-183-3p exhibited inhibition property in the proliferation and migration of HaCaT cells via downregulation of GAB1, suggesting the potential therapeutic strategy for psoriasis.
\end{abstract}

Keywords: miR-183-3p, GAB1, Psoriasis, Keratinocytes, Proliferation, Migration

\section{Background}

Psoriasis is a common chronic inflammatory disease, with increasing incidence and a prevalence between 1 and 3\% worldwide [1]. The etiology and pathogenesis of psoriasis is complicated and still unclear. Currently, it is believed that the pathogenesis of psoriasis mainly involves immune, genetic, psychological and environmental factors [2]. The main pathological changes of psoriasis are keratinocyte dysplasia, keratinosis, neovascularization and inflammatory cell infiltration [3]. Meanwhile, hyperproliferation and abnormal migration of keratinocytes, responsible for

\footnotetext{
*Correspondence: DCVB90oi@163.com

Department of Dermatology, Affiliated Hospital of North Sichuan Medical College, No. 1, Maoyuan South Road, Nanchong City 637000, Sichuan Province, China
}

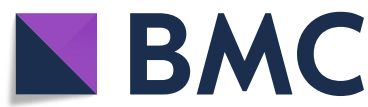

(c) The Author(s). 2020 Open Access This article is licensed under a Creative Commons Attribution 4.0 International License, which permits use, sharing, adaptation, distribution and reproduction in any medium or format, as long as you give appropriate credit to the original author(s) and the source, provide a link to the Creative Commons licence, and indicate if changes were made. The images or other third party material in this article are included in the article's Creative Commons licence, unless indicated otherwise in a credit line to the material. If material is not included in the article's Creative Commons licence and your intended use is not permitted by statutory regulation or exceeds the permitted use, you will need to obtain permission directly from the copyright holder. To view a copy of this licence, visit http://creativecommons.org/licenses/by/4.0/ The Creative Commons Public Domain Dedication waiver (http://creativecommons.org/publicdomain/zero/1.0/) applies to the data made available in this article, unless otherwise stated in a credit line to the data.

psoriasis lesional microenvironment, are critical features of psoriasis [4]. Considering the fact that psoriasis is easy to relapse and difficult to cure, exploringnew therapeutical targets involved in the proliferation and migration of keratinocytes is beneficial for the cure of psoriasis.

MiRNAs (microRNAs), with a length of about 18-25 nucleotides, are a class of non-coding single-stranded small RNA molecules that are highly conserved in evolution and ubiquitous in plants and animals [5]. MiRNAs account for $1-5 \%$ of the entire human genome and regulate the expression of $30 \%$ of protein-coding genes in human [5]. MiRNAs could bind to the 3'UTR of a specific target gene mRNA through base complementary pairing to degrade its target mRNA or inhibit its translation, thereby negatively regulate protein expression at 
post-transcriptional levels [5]. Moreover, miRNAs have the abilities to regulate cell proliferation and immune response, are critically implicated in the pathogenesis of immunological disorders, including psoriasis [6]. For example, Sonkoly et al. found that miR-203 could inhibit the expression of suppressor of cytokine signaling-3, which was involved in the inflammatory response of keratinocyte [7]. MiR-125b reduced the expression of fibroblast growth factor receptor 2 to regulate the proliferation and differentiation of keratinocytes [8]. MiR4516 could reduce the proliferatory and migratory abilities of keratinocytes toameliorate psoriasis [9].

MiR-183-3p was found to be associated with chronic systolic heart failure [10] and lung adenocarcinoma [11]. More recently, miR-183-5p was identified as a mediator of inflammatory disease and involved in the chronic constriction injury-induced neuropathic pain [12],. Besides, down-regulation of miR-183-3p was also discovered in psoriatic skin [13]. However, the role and mechanism of miR-183-3p in psoriasis remains elusive. Therefore, this study aimed to examine the functional role of miR-183$3 p$ in the proliferation and migration of keratinocytes, and identified the underlying mechanism, thus providing more potential therapeutic strategy for psoriasis.

\section{Results}

MiR-183-3p was down-regulated in psoriatic lesional skin To evaluate the expression level of miR-183-3p in psoriatic patients, 41 paired psoriatic lesional (LS) or nonlesional (Con) skin biopsies were collected and qRTPCR was peformed. Result showed a significant reduction of miR-183-3p in LS compared to Con (Fig. 1a). Moreover, ISH showed that higher expression of miR183-3p in Con group was found in basal and suprabasal cell layers than that in LS group (Fig. 1b). In general, miR-183-3p was down-regulated in psoriatic lesional skin.

\section{Over-expression of miR-183-3p suppressed keratinocytes cell proliferation and migration}

To evaluate the biological role of miR-183-3p in keratinocyte, $\mathrm{HaCaT}$ cells were transfected with miR-183-3p mimics or inhibitor, and the transfection efficiency was validated by qRT-PCR (Fig. 2a). CCK8 assay revealed that over-expression of miR-183-3p inhibited $\mathrm{HaCaT}$ cell viability (Fig. 2b), while inhibition of miR-183-3p promoted HaCaT cell viability (Fig. 2b). Moreover, the migration of $\mathrm{HaCaT}$ cells was inhibited by miR183-3p mimics (Fig. 2c), while promoted by miR-1833p inhibitor (Fig. 2c). Therefore, over-expression of miR-183-3p suppressed keratinocytes cell proliferation and migration.

\section{MiR-183-3p negatively regulated GAB1 expression in keratinocytes}

Thebinding site of miR-183-3p was predicted and results demonstrated that 3' UTR of GAB1 harbored putative binding site for miR-183-3p (Fig. 3a). The dual luciferase assay indicated that ectopic expression of miR-183-3p repressed the luciferase activity of pmirGLO-wt-GAB1 (Fig. 3b), while this inhibitory effect was abolished by transfection with pmirGLO-mut-GAB1 (Fig. 3b). In addition, miR-183-3p mimics reduced the mRNA and protein expression of GAB1, while GAB1 expression was increased in $\mathrm{HaCaT}$ cells after transfected with miR-183-3p inhibitor (Fig. 3c and d). Taken together, miR-183-3p negatively regulated GAB1 expression in keratinocytes.

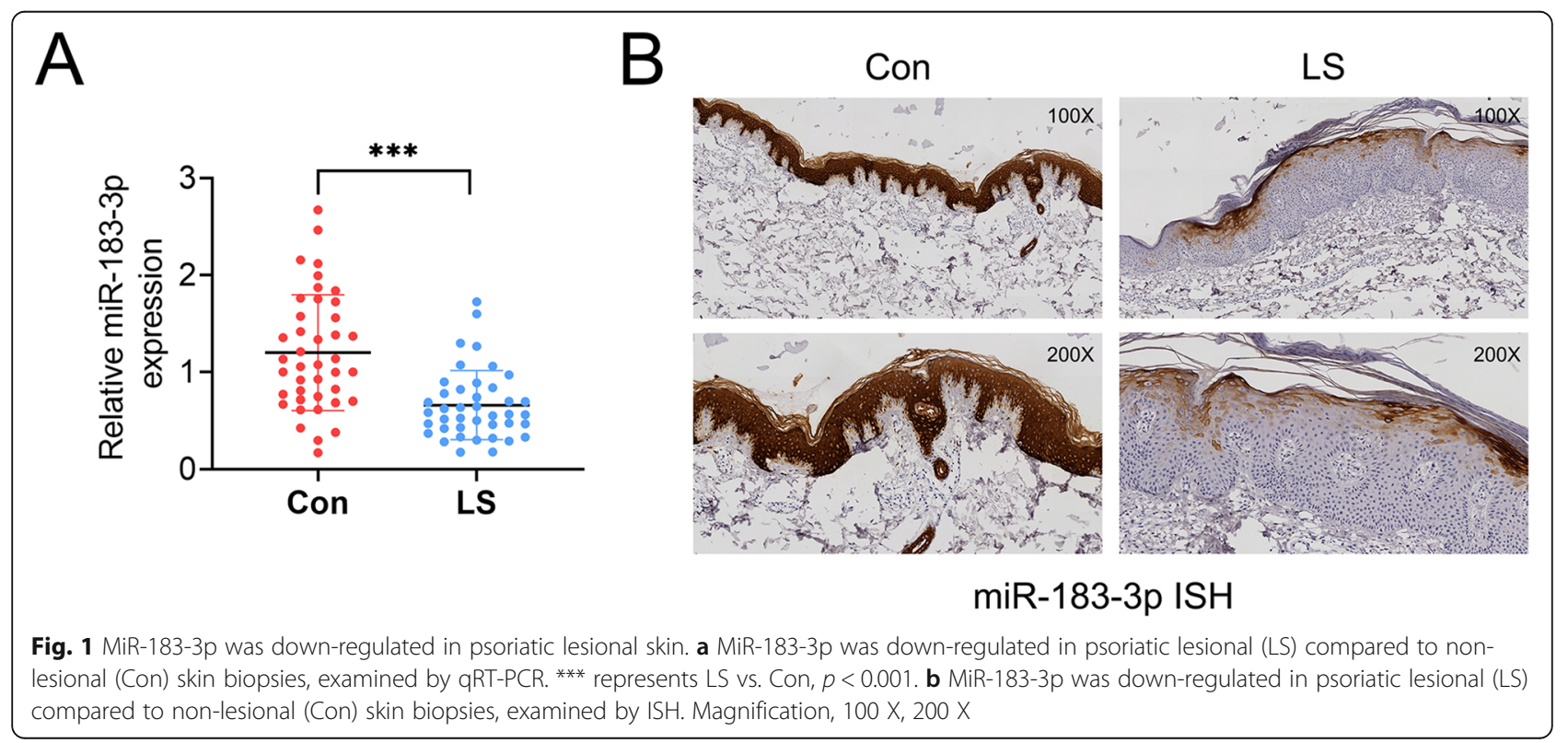



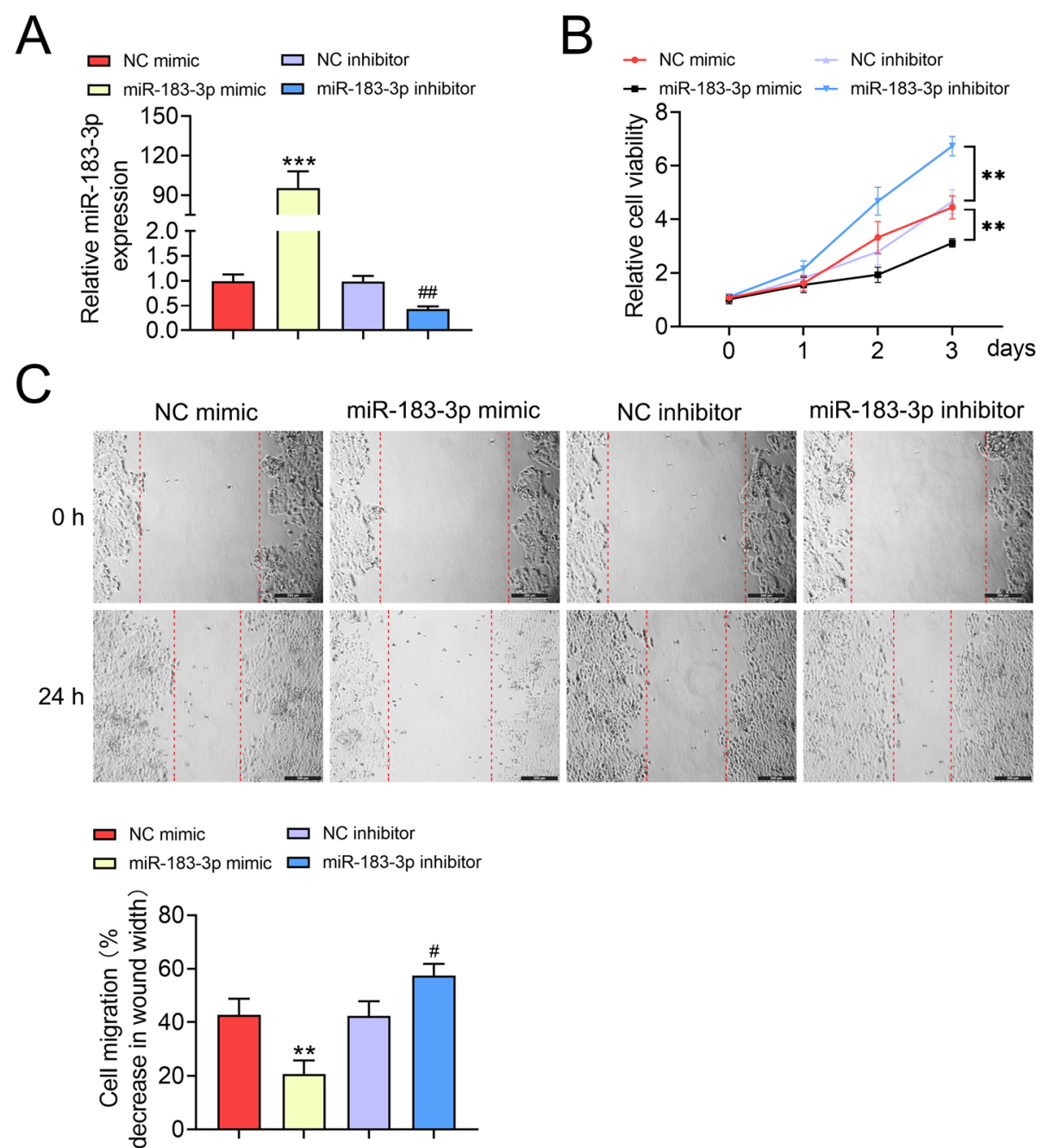

Fig. 2 Over-expression of miR-183-3p suppressed keratinocytes cell proliferation and migration. a Transfection efficiency of miR-183-3p mimics or inhibitor in HaCaT cells. *** represents miR-183-3p mimics vs. NC mimic, $p<0.001$. \#\# represents miR-183-3p inhibitor vs. NC inhibitor, $p<0.01$. $\mathbf{b}$ MiR-183-3p decreased the viability of HaCaT cells, while miR-183-3p inhibitor increased the viability of HaCaT cells. ${ }^{* *}$ represents miR-183-3p mimics vs. NC mimic, $p<0.01$. \#\# represents miR-183-3p inhibitor vs. NC inhibitor, $p<0.01$. c MiR-183-3p inhibited the migration of HaCaT cells, while miR-183-3p inhibitor promoted the migration of HaCaT cells. ** represents miR-183-3p mimics vs. NC mimic, $p<0.01$. \# represents miR-183$3 p$ inhibitor vs. NC inhibitor, $p<0.05$

GAB1 was up-regulated in psoriatic lesional skin Considering the negative corrlation between miR-183-3p and GAB1, the expression of GAB1 in psoriatic lesional skin was then determined. Results fromqRT-PCR (Fig. 4a) and immunohistochemistry (Fig. 4b) showed that GAB1 was elevated in LS group compared to Con group. Moreover, the correlation analysis indicated a significantly negative correlation $(p=0.0033)$ between miR183-3p and GAB1 in psoriatic patients (Fig. 4c).

\section{Discussion}

Increasing evidence has revealed that miRNAs were abnormally expressed in psoriasis, and regulate immune dysfunction and keratinocytes proliferation in psoriasis [6]. Results from this study revealed the downregulation of miR-183-3p in psoriatic lesional skin, which were consistent with a previous report [13], indicating its regulatory role in the progression of psoriasis.

Psoriasis is a complicated disease resulting from the dysregulated interplay between keratinocytes, immune cells and other skin-resident cells [14]. Hyperproliferation of keratinocytes could result in tacanthosis, infiltration of immunocytes in the epidermis that are resemble with psoriasis lesional microenvironment [15]. Moreover, the migration of keratinocytes could promote wound reepithelialization and recapitulate psoriasis lesional microenvironment [16]. Inhibition of keratinocytes proliferation and migration could be beneficial for psoriasis [9]. This study also demonstrated that ectopic expression of miR-183-3p inhibited keratinocytes proliferation and 


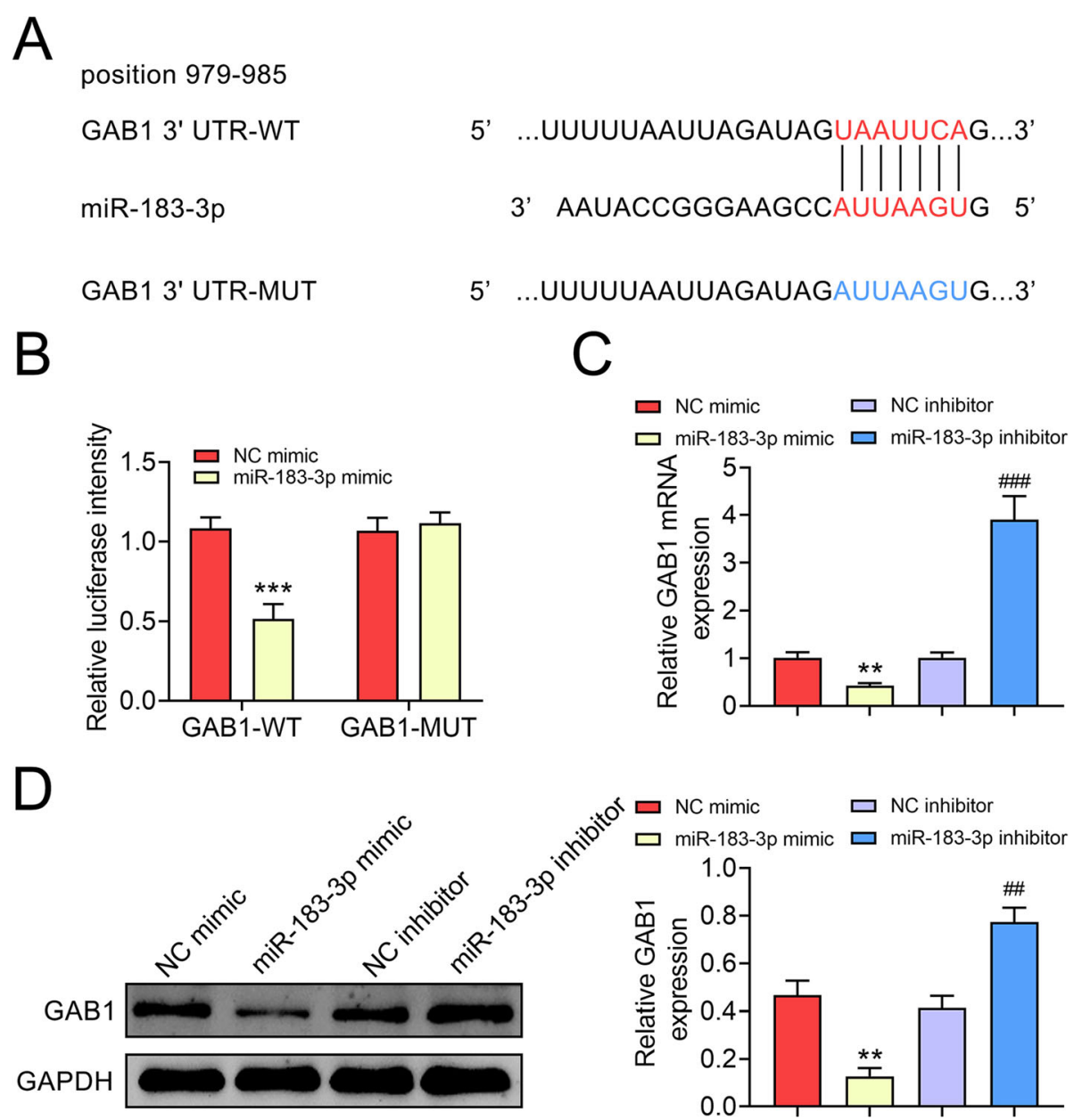

Fig. 3 MiR-183-3p negatively regulated GAB1 expression in keratinocytes. a Putative binding sites between GAB1 and miR-183-3p. b MiR-183-3p decreased the luciferase activity of pmirGLO-wt-GAB1 compared to pmirGLO-mut-GAB1 in HaCaT cells. *** represents miR-183-3p mimics vs. NC mimic, $p<0.001$. c MiR-183-3p decreased mRNA expression of GAB1 in HaCaT cells, while miR-183-3p inhibitor increased GAB1 expression. ${ }^{* *}$ represents miR-183-3p mimics vs. NC mimic, $p<0.01$. \#\#\# represents miR-183-3p inhibitor vs. NC inhibitor, $p<0.001$. d MiR-183-3p decreased protein expression of GAB1 in HaCaT cells, while miR-183-3p inhibitor increased GAB1 expression. ** represents miR-183-3p mimics vs. NC mimic, $p<0.01$. \#\# represents miR-183-3p inhibitor vs. NC inhibitor, $p<0.01$

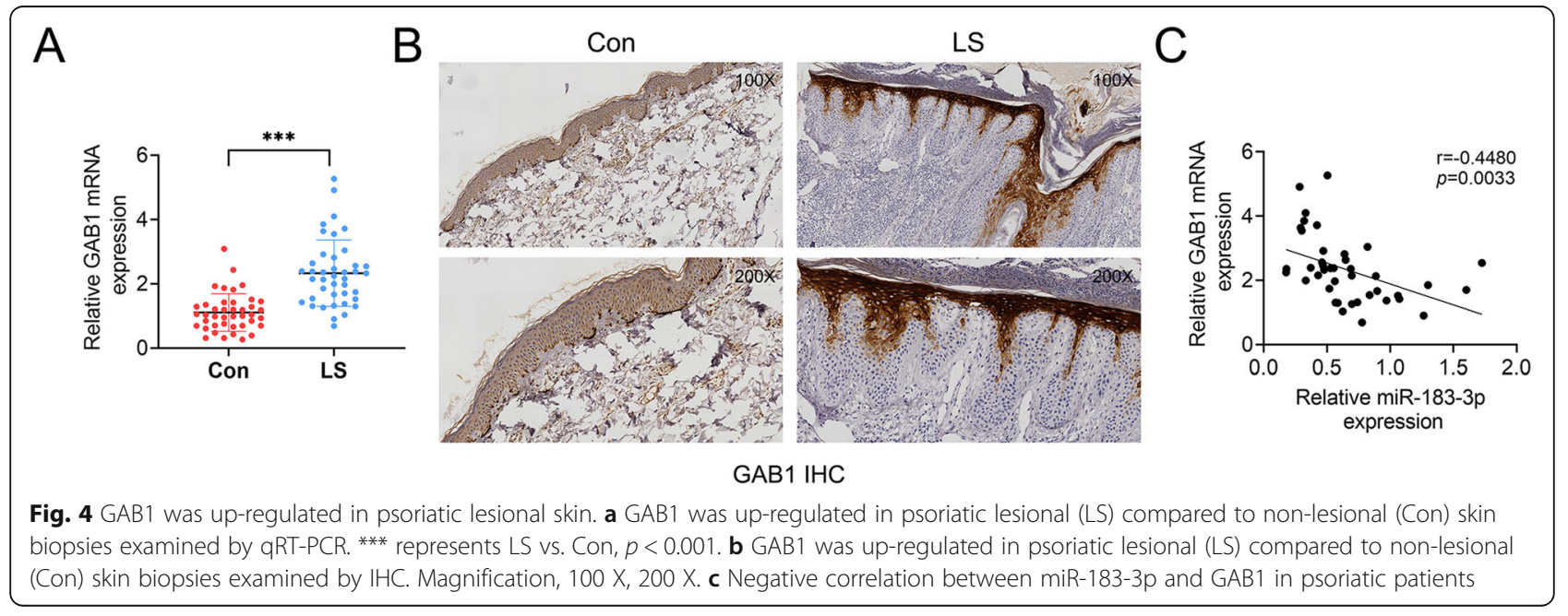


migration, while inhibition of miR-183-3p promoted keratinocytes proliferation and migration. Moreover, keratinocytes are rekated to cell apoptosis in psoriasis [17], and inhibition of cell apoptosis contribute to the amelioration of psoriasis (MiR-20a-3p regulates TGF- $\beta 1 /$ Survivin pathway to affect keratinocytes proliferation and apoptosis by targeting SFMBT1 in vitro). Therefore, the role of miR-183-3p in the apoptosis of keratinocytes should be investigated in the further study. In addition, psoriasis is also a chronic inflammatory disease [1], accumulation of proinflammatory factor can exacerbate psoriasis [18]. Numerous inflammatory cytokines secreted from immune cells could contribute to the proliferation of keratinocytes [19]. IL22, up-regulated in lesional skins of patients with psoriasis [20], could bind to the receptor in keratinocytes and promote the cell proliferation [21], thus is critical for the pathogenesis of psoriasis. Additionally, miR-183, abnormally expressed in autoimmune diseases, plays key role in immunity [22]. MiR-183c could suppress Th17 cell pathogenic function [23], which is also important for psoriasis. Further investigations should concernthe effect of miR-183-3p on inflammation during psoriasis.

Bcl-2 interacting protein 3 like [10] or high-mobility group nucleosome binding domain 5 [24] were validated as binding targets of miR-183-3p and involved in chronic systolic heart failure or prostate cancer, respectively. The direct binding target involved in miR-183-3pmediated psoriasis remains elusive. This is the first study identifing GAB1 as a binding target of miR-183-3p during psoriasis. GAB1 functions as a docking protein to promote the proliferation and differentiation of epidermis [25]. Moreover, GAB1 was found to be involved in the migration of keratinocyte, as well as wound healing, suggesting its potential role in the pathogenesis of psoriasis [26]. Recently, GAB1 was shown to be aberrantly expressed in multiple sclerosis and psoriasis [27]. Results from this study showed that GAB1 was up-regulated in psoriatic lesional skin, and suggested a significantly negative correlation with miR-183-3p. In addition, miR-183-3p could repress the mRNA and protein expression of GAB1, suggesting that miR-183-3p could suppress the proliferation and migration of keratinocyte in psoriasis by inhibiting GAB1. Ras [25] and phosphoinositide 3-kinase pathway [26] were closely associated with GAB1-mediated epidermal differentiation and cell proliferation/migration in cultured skin keratinocytes, respectively. The underlying mechanism related to miR-183-3p/GAB1 axismediated psoriasis needs further investigations.

\section{Conclusion}

In conclusion, miR-183-3p effectively suppressed the viability and migration of keratinocytes through downregulation of GAB1. These results suggested the beneficial effect of miR-183-3p knockdown during psoriasis.

\section{Methods}

\section{Patients and specimens}

Forty-one paired lesional or non-lesional skin biopsies $(5 \mathrm{~mm})$ were collected from patients who diagnosed as psoriasis at the Affiliated Hospital of North Sichuan Medical College. The protocol was approved by the Ethics Committee of Affiliated Hospital of North Sichuan Medical College, and all patients signed written informed consent.

\section{In situ hybridization}

Formalin-fixed and paraffin-embedded sections $(5 \mu \mathrm{m}$ in thickness) of the biopsy specimens were firstly incubated with acetylation solution for $10 \mathrm{~min}$, and then incubated with permeabilization buffer for $30 \mathrm{~min}$. After prehybridizing at $50{ }^{\circ} \mathrm{C}$ for $1 \mathrm{~h}$, the sections were hybridized with digoxygenin-labeled miRCURY locked nucleic acid probes (Exiqon, Vedbaek, Denmark) overnight. After incubation with alkaline phophatase-conjugated sheep antidigoxigenin Fab fragments (1:3000, Abcam, Cambridge, MA, USA) for $1 \mathrm{~h}$, the sections were visualized under inverted microscope (Nikon Eclipse Ti, Tokyo, Japan).

\section{Immunohistochemistry}

Formalin-fixed and paraffin-embedded sections $(0.5 \mu \mathrm{m}$ in thickness) of the biopsy specimens were incubated with rabbit antihuman GAB1 antibody (1:500, Abcam) overnight. After incubation with horse radish peroxidase-goat anti-rabbit secondary antibody, the sections were visualized under inverted microscope.

\section{Cell culture}

$\mathrm{HaCaT}$ cells were cultured in $37^{\circ} \mathrm{C}$ constant temperature incubator with $5 \% \mathrm{CO}_{2}$ in DMEM F-12 media (Life Technologies, Gaithersburg, MD, USA) with $10 \%$ fetal bovine serum (Gibco, Grand Island, NY, USA) and streptomycin $(100 \mu \mathrm{g} / \mathrm{ml})$ and penicillin $(100 \mathrm{U} / \mathrm{ml})$.

\section{Cell transfection}

MiR-183-3p mimics, inhibitor and the negative controls (NC mimic, NC inhibitor) were synthesized by GenePharma (Suzhou, China). HaCaT cells $\left(1 \times 10^{6}\right.$ per well $)$ were seeded and then transfected with miR-183-3p mimics/inhibitor $(20 \mathrm{nM})$ or their negative controls (NC) via Lipofectamine 2000. The transfection efficiency was validated by qRT-PCR $48 \mathrm{~h}$ after transfection.

\section{Cell viability}

$\mathrm{HaCaT}$ cells $\left(1 \times 10^{4}\right.$ cells/well $)$ were seeded and then transfected with miR-183-3p mimics/inhibitor (20 nM) or their NC. Forty-eight hours later, each well was supplemented with $10 \mu \mathrm{L}$ CCK8 solution (Dojindo, Tokyo, Japan) for $1 \mathrm{~h}$. Absorbance at $450 \mathrm{~nm}$ for each well was determined via Microplate Autoreader (Thermo Fisher, 
Waltham, MA, USA) every $24 \mathrm{~h}$ intervals at $0,24,48,72$ h.

\section{Wound healing}

$\mathrm{HaCaT}$ cells $\left(1 \times 10^{4}\right.$ cells/well $)$ were seeded and then transfected with miR-183-3p mimics/inhibitor (20 nM) or their NC. After transfection for $48 \mathrm{~h}$, each well was scratched and then cultured for another $24 \mathrm{~h}$. Wound area was photographed and calculated.

\section{Dual luciferase reporter assay}

Sequences of wildtype or mutant of GAB1 3'-UTR were constructed into pmirGLO luciferase reporter vector (Promega, Madison, Wisconsin, USA). The seeded $\mathrm{HaCaT}$ cells were co-transfected with miR-183-3p mimics or NC mimic and pmirGLO-wt-GAB1 or pmirGLO-mut-GAB1. Two days later, the luciferase activities were determined via Lucifer Reporter Assay System (Promega).

\section{qRT-PCR}

RNAs or miRNAs were isolated from psoriatic lesional or non-lesional skin and $\mathrm{HaCaT}$ cells via Trizol (Thermo Fisher). Total RNAs or miRNAs were then reversetranscribed into cDNAs via High Capacity Reverse Transcription System Kit (Takara, Dalian, China) or MicroRNA Reverse Transcription Synthesis Kit (Thermo Fisher). qRT-PCR was conducted with SYBR Green Master (Roche, Mannheim, Germany) on Applied Biosystems 7500 Real-time PCR Systems (Thermo Fisher). GAPDH or U6 was used as endogenous control with the following primer sequences (Table 1).

\section{Western blot}

Proteins were extracted from $\mathrm{HaCaT}$ cells and subjected to SDS-PAGE. After transferring onto PVDF membrane and blocking by $5 \%$ BSA, the membranes were then incubated with primary antibodies: anti-GAB1 (1:1500, Abcam) and GAPDH (1:3000, Abcam), followed by incubulation with HRP labeled secondary antibody (Sungene, Tianjin, China). The immunoreactivities were determined by Millipore ECL (Billerica, MA, USA).

Table 1 Primer

\begin{tabular}{ll}
\hline ID & Sequence $\left(5^{\prime}\right.$ - 3') $^{\prime}$ \\
\hline GAPDH F & TATGATGATATCAAGAGGGTAGT \\
miR-183-3p F & TGTATCCAAACTCATTGTCATAC \\
miR-183-3p R & CGCGGTATGGCACTGGTAGA \\
GAB1 F & AGTGCAGGGTCCGAGGTATTC \\
GAB1 R & ATGAGCGGCGGCGAAGTGGTTGCT \\
U6F & CGCGACTGAAGAAGCTTCCATCTGA \\
U6 R & CTCGCTTCGGCAGCACA \\
\hline
\end{tabular}

\section{Statistical analysis}

Data were shown as mean \pm SEM and analyzed by Graphpad Prism 6. The statistical analyses were determined with one-way analysis of variance at significance of * $p<0.05, * * p<0.01$ or $* * p<0.001$. The correlation between GAB1 and miR-183-3p expression was determined by Spearman's correlation coefficients.

\section{Abbreviations \\ miRNAs: MicroRNAs; ISH: In situ hybridization; HaCaT: Human keratinocyte cell line}

\section{Acknowledgements}

Not applicable.

\section{Authors' contributions}

TL conceived and designed the experiments, $X Y Z$ analyzed and interpreted the results of the experiments, YJW performed the experiments. The authors read and approved the final manuscript.

Funding

None.

Availability of data and materials

All data generated or analyzed during this study are included in this published article.

Ethics approval and consent to participate

The protocol was approved by the Ethics Committee of Affiliated Hospital of North Sichuan Medical College.

\section{Consent for publication}

All the patients signed written informed consent.

\section{Competing interests}

The authors state that there are no conflicts of interest to disclose.

Received: 8 April 2020 Accepted: 30 June 2020

Published online: 10 July 2020

References

1. GR LL, Du Thanh A. Squamous cell carcinoma antigen elevation in cervical cancer follow-up: the forest hiding the tree. Eur J Gynaecol Oncol. 2018;39: 324-6.

2. Nickoloff BJ, Qin JZ, Nestle FO. Immunopathogenesis of psoriasis. Clin Rev Allergy Immunol. 2007;33:45-56.

3. Zhang $Y$, Tu $C$, Zhang D, Zheng Y, Peng Z, Feng $Y$, et al. Wnt/beta-catenin and Wnt5a/ca pathways regulate proliferation and apoptosis of keratinocytes in psoriasis lesions. Cell Physiol Biochem. 2015;36:1890-902.

4. Albanesi C, De Pita O, Girolomoni G. Resident skin cells in psoriasis: a special look at the pathogenetic functions of keratinocytes. Clin Dermatol. 2007;25: 581-8.

5. Sotiropoulou G, Pampalakis G, Lianidou E, Mourelatos Z. Emerging roles of MicroRNAs as molecular switches in the integrated circuit of the cancer cell. RNA (New York, NY). 2009;15:1443-61

6. Liu Q, Wu DH, Han L, Deng JW, Zhou L, He R, et al. Roles of microRNAs in psoriasis: immunological functions and potential biomarkers. Exp Dermatol. 2017;26:359-67.

7. Sonkoly E, Wei T, Janson PCJ, Sääf A, Lundeberg L, Tengvall-Linder M, et al. MicroRNAs: novel regulators involved in the pathogenesis of psoriasis? PLoS One. 2007:2:e610.

8. Xu N, Brodin P, Wei T, Meisgen F, Eidsmo L, Nagy N, et al. MiR-125b, a microRNA downregulated in psoriasis, modulates keratinocyte proliferation by targeting FGFR2. J Invest Dermatol. 2011;131:1521-9.

9. Chowdhari S, Sardana K, Saini N. miR-4516, a microRNA downregulated in psoriasis inhibits keratinocyte motility by targeting fibronectin/integrin alpha9 signaling. Biochimica Et Biophysica Acta Mol Basis Dis. 2017;1863: 3142-52. 
10. Ouyang S, Chen W, Zeng G, Lei C, Tian G, Zhu M, et al. MicroRNA-183-3p up-regulated by vagus nerve stimulation mitigates chronic systolic heart failure via the reduction of BNIP3L-mediated autophagy. Gene. 2020;726: 144136.

11. Xu F, Zhang H, Su Y, Kong J, Yu H, Qian B. Up-regulation of microRNA-183$3 p$ is a potent prognostic marker for lung adenocarcinoma of female nonsmokers. Clin Transl Oncol. 2014;16:980-5.

12. Shi D-N, Yuan Y-T, Ye D, Kang L-M, Wen J, Chen H-P. MiR-183-5p alleviates chronic constriction injury-induced neuropathic pain through inhibition of TREK-1. Neurochem Res. 2018;43:1143-9.

13. Zibert JR, Løvendorf MB, Litman T, Olsen J, Kaczkowski B, Skov L. MicroRNAs and potential target interactions in psoriasis. J Dermatol Sci. 2010;58:177-85.

14. Benhadou F, Mintoff D, Del Marmol V. Psoriasis: keratinocytes or immune cells - which is the trigger? Dermatology. 2019;235:91-100.

15. Garzorz-Stark N, Eyerich K. Psoriasis pathogenesis: keratinocytes are Back in the spotlight. J Investig Dermatol. 2019;139:995-6.

16. Ortonne JP. Aetiology and pathogenesis of psoriasis. Br J Dermatol. 1996; 135:1-5.

17. Korkmaz S, Korkmaz H. Effect of alterations in apoptotic pathway on development of metabolic syndrome in patients with psoriasis vulgaris. $\mathrm{Br} \mathrm{J}$ Dermatol. 2017;176:1549-57.

18. Niu X-L, Huang Y, Gao Y-L, Sun Y-Z, Han Y, Chen H-D, et al. Interleukin-18 exacerbates skin inflammation and affects microabscesses and scale formation in a mouse model of imiquimod-induced psoriasis. Chin Med J. 2019;132:690-8.

19. Litvinov IV, Bizet AA, Binamer Y, Jones DA, Sasseville D, Philip A. CD109 release from the cell surface in human keratinocytes regulates TGF- $\beta$ receptor expression, TGF- $\beta$ signalling and STAT3 activation: relevance to psoriasis. Exp Dermatol. 2011;20:627-32.

20. Mashiko S, Bouguermouh S, Rubio M, Baba N, Bissonnette R, Sarfati M. Human mast cells are major IL-22 producers in patients with psoriasis and atopic dermatitis. J Allergy Clin Immunol. 2015;136:351-9 e1.

21. Shen $H$, Zeng B, Wang C, Tang X, Wang H, Liu W, et al. MiR-330 inhibits IL22-induced keratinocyte proliferation through targeting CTNNB1. Biomed Pharmacother. 2017;91:803-11.

22. Ichiyama K, Dong C. The role of miR-183 cluster in immunity. Cancer Lett. 2019:443:108-14.

23. Ichiyama K, Gonzalez-Martin A, Kim BS, Jin HY, Jin W, Xu W, et al. The MicroRNA-183-96-182 cluster promotes T helper 17 cell pathogenicity by negatively regulating transcription factor Foxo1 expression. Immunity. 2016; 44:1284-98.

24. Li Y, He S, Zhan Y, He A, Gong Y, Ji G, et al. microRNA-183-3p inhibits progression of human prostate cancer by downregulating high-mobility group nucleosome binding domain 5. DNA Cell Biol. 2019;38:840-8.

25. Cai T, Nishida K, Hirano T, Khavari PA. Gab1 and SHP-2 promote Ras/MAPK regulation of epidermal growth and differentiation. J Cell Biol. 2002;159: 103-12.

26. Y-m Z, Zhang Z-q, Y-y L, Zhou X, Shi X-h, Jiang Q, et al. Requirement of Gai1/3-Gab1 signaling complex for keratinocyte growth factor-induced PI3K-AKT-mTORC1 activation. J Invest Dermatol. 2015;135:181-91.

27. Sharma A, Menche J, Huang CC, Ort T, Zhou X, Kitsak M, et al. A disease module in the interactome explains disease heterogeneity, drug response and captures novel pathways and genes in asthma. Hum Mol Genet. 2015; 24:3005-20

\section{Publisher's Note}

Springer Nature remains neutral with regard to jurisdictional claims in published maps and institutional affiliations.

\section{Ready to submit your research? Choose BMC and benefit from:}

- fast, convenient online submission

- thorough peer review by experienced researchers in your field

- rapid publication on acceptance

- support for research data, including large and complex data types

- gold Open Access which fosters wider collaboration and increased citations

- maximum visibility for your research: over $100 \mathrm{M}$ website views per year

At BMC, research is always in progress.

Learn more biomedcentral.com/submissions 